\title{
Spatial Patterns of Local Income Inequalities
}

\author{
Ibolya TÖRÖK'1, József BENEDEK'1 \\ ${ }^{1}$ Babeş-Bolyai University, Faculty of Geography, Centre for Sustainable Development, Cluj-Napoca, ROMANIA \\ E-mail: ibolya.torok@ubbcluj.ro, jozsef.benedek@ubbcluj.ro \\ DOI: 10.24193/JSSP.2018.2.01 \\ https://doi.org/10.24193/JSSP.2018.2.01
}

K e y w O r d s: local income, inequality, spatial clusters of income distribution, exploratory spatial data analysis, Romania

\begin{abstract}
A B S T R A C T
The main aim of this study is to describe the spatial patterns of local income inequalities by employing techniques of spatial exploratory data analysis. Global and local measures of spatial autocorrelation were computed in order to obtain estimates for the existing spatial autocorrelation at the local income level. Using this information, we determined the spatial clusters of significantly auto-correlated local income distribution. The first major result of the paper consists in the measurement of the local income levels, an innovative contribution to the advancement in this field since there are no official statistics on local level economic data in Romania. The second major result of the paper consists in the identification and delineation of specific spatial structures at high spatial resolution. It enables the precise designation of peripheral regions for spatial planning interventions. The third major outcome of the paper brings empirical evidence for the existence of highly significant spatial interactions and for the strong spatial interconnections between areas of similar local income levels.
\end{abstract}

\section{INTRODUCTION}

The political and economic changes at the beginning of the 1990 s have brought about considerable changes in the spatial structure of Romania. The processes of economic privatisation, industrial restructuring, suburbanisation and out-migration have contributed substantially to the restructuring of the Romanian economic space [1], [2], [3], marked by increasing spatial, and socio-economic inequalities [4], [5], [6].

The severe economic decline in the 1990s, followed by a period of high economic growth (19992008) have put their mark on the development of settlements and regions. While some regions have successfully adapted to the new challenges (the capitalregion of Bucharest, the metropolitan regions of Cluj, Constanța, and Timișoara) others have faced a deep crisis (the rural peripheries, mining and heavy industrial regions) [7], [8]. Growing interregional income inequalities have also represented one of the main concerns of the EU Member States.

Although the European Cohesion Policy specifically addresses the issue of regional inequalities, so far empirical research has shown its increasing tendency during the last two decades at sub-national level [9], [10], [11], [12], [13]. Studies examining the convergence process in the European Union from a multidimensional perspective, before and after the accession period, at different territorial scales, have shown that economic growth has been much higher in Central and Eastern European (CEE) countries with a more homogenous spatial structure and a lower level of initial GDP per capita [14], [15], [16].

This has also been the case of Romania, the country managing to achieve convergence at NUTS 1 level (Nomenclature of Territorial Units for Statistics) with the EU average, although this was achieved at the cost of an increasing internal, sub-national divergence [17], [6]. 
Furthermore, the recent economic and financial crisis has aggravated the pre-existing regional problems even more [18], [19]. Although in the last decade a series of studies have dealt with the issue of regional disparities in Romania [20], [21], [22], there is a considerable research gap related to their exclusive focus on the NUTS 3 level (counties), mainly due to the lack of economic data on local level.

This study aims to fill this gap by analysing the local income at NUTS 5 level (urban and rural settlements). More exactly, we will examine the spatial distribution and the global and local spatial autocorrelation of local income, using different exploratory spatial data analysis (ESDA) techniques [23].

In section 1 we briefly present the ESDA techniques highlighting the main characteristics of global and local Moran's I as well as the $\mathrm{Gi}^{*}$ statistic. Section 2 presents the main patterns of local income inequalities. Section 3 gives detailed empirical results for income per capita distribution, by computing the Getis-Ord Gi* statistic for the determination of high and low income level clusters.

In this section we use Moran scatter plot in order to examine the existence of spatial autocorrelation, and Local Indicators of Spatial Association (LISA) for revealing spatial outliers or “atypical localizations".

The most important findings of the analysis will be outlined in the last section, dedicated for conclusions.

\section{MATERIAL AND METHODS}

The analysis of spatial inequalities in Romania was based on existing territorial statistical data obtained from the Romanian National Institute of Statistics (INS), including the 2011 Census, the Tempo Online database as well as the database obtained from the Regional Directorates General of Public Finance (ANAF) [24], [25].

The latter represents the core database of our analysis, namely the income of local public administration (cities and communes) in 2013. We outline the distinctiveness of this data set, as generally GDP per capita or household incomes are used as income variables. In Romania, neither GDP per capita nor household incomes are calculated at NUTS 5 level.

Local incomes in Romania are divided into two different categories: taxes and fees collected by the local authority (including grants from central budgets) and fees collected by each local public service provider. Monthly, the local public administration authorities get the majority of financial resources directly from the National Fiscal Administration Agency, which is responsible with collecting the major taxes (income tax, VAT, corporate tax etc.).
Taxes administrated by local authorities are mostly property taxes (on buildings, lands and cars) and authorizations in construction [26]. Overall, these databases enable us to use data on all incomes generated at local level corresponding to the EU NUTS 5 level, represented by 2,861 communes and 320 cities. The incomes represented by local taxes and revenues collected from individuals and companies is a good approximation of the locally generated economic output. At the same time, it is the only way to estimate local incomes in Romania.

The identification and delineation of spatial clusters of the income per capita distribution was based on the use of ESDA. The most interesting feature of spatial autocorrelation is its ability to analyze location and attribute information at the same time [27]. Spatial autocorrelation tests whether the value of an observed variable is independent of the values of the same variable in neighbouring settlements [28].

The most prominent authors in exploring and using spatial autocorrelation were [29], [28] who have developed Moran's I statistic for measuring (global) spatial autocorrelation [30] (Eq. 1).

$$
I=\frac{\sum_{i=1}^{n} \sum_{j=1}^{n} w_{i j}\left(x_{i}-\bar{x}\right)\left(x_{j}-\bar{x}\right)}{\sum_{i=1}^{n} \sum_{j=1}^{n} w_{i j} \sum_{i=1}^{n}\left(x_{i}-\bar{x}\right)},
$$

where:

$I$ - global Moran's;

$\mathrm{I}, x_{i}$ - value of the monitored variable in unit $\mathrm{i}$;

$i, x_{j}-$ value of the monitored variable in unit $\mathrm{j}$;

$j, x$ with stripe - arithmetic average of the monitored variable;

$w_{i j}$ - generic element of contiguity matrix.

The concept of contiguity can be defined as a generalized matrix of $\mathrm{W}$ weight, usually symmetrical, representing the pattern of connections or ties and their intensity [31], where $w_{i}$ weightsj denote the effect of the territorial unit on unit $i$. In this study, a dichotomy matrix of contiguity was used where $w_{i j}=1$ if the $i$ area touches the boundary of $j$ area, otherwise $w_{i j}=o$.

The weighing matrix is row standardized, and the weights are defined as:

$$
\mathcal{W}_{i j}^{s}=\frac{\mathcal{W}_{i j}}{\sum_{j} \mathcal{W}_{i j}}, \text { such that } \sum_{j} \boldsymbol{W}_{i j}^{s}=1
$$

The row standardization has two important implications, namely: it implies equal weights across neighbours of the same settlement and it implies that the sum over all elements of the row-standardized 
weight matrix $\left(w_{i j}^{s}\right)$ is equal to the total number of observations (N) (Eq. 2).

Therefore, the equation can be rewritten as:

$$
I^{s}=\frac{\sum_{i, j} w_{i j}^{s}\left(x_{i}-\bar{x}\right)\left(x_{j}-\bar{x}\right)}{\sum_{i}\left(x_{i}-\bar{x}\right)^{2}}
$$

The appropriate or most adequate choice of the spatial weight matrix is one of the most difficult methodological issues in ESDA techniques, as the final results depend on using contiguity weights or distance weights. In the analysis we compared both of them, applying 1, 2, 3 and 4 queen contiguity weights against to k-nearest distance weight.

The closer the value of Moran's I to -1 or +1 , the stronger the spatial autocorrelation. While global Moran's I measures the spatial autocorrelation as a whole, suggesting that the spatial pattern of the analyzed index we observe is not random, LISA allows us to quantify the degree of spatial autocorrelation at each specific location and also indicates the atypical localizations [32] (Eq. 3).

$$
I_{i}=\frac{\left(x_{i}-\bar{x}\right) \sum_{j=1}^{n} w_{i j}\left(x_{j}-\bar{x}\right)}{\sum_{i=1}^{n}\left(x_{i}-\bar{x}\right)^{2}}
$$

A high positive local Moran's I value indicate that the location under study is surrounded by locations with similar values of the observed variable. This location is then part of the cluster, which includes highhigh clusters (high values in a high value neighbourhood) and low-low clusters (low values in a low value neighbourhood).

On the other hand, the negative value of local Moran's I means that the analyzed location is a spatial outlier, which includes high-low clusters (high values are surrounded particularly by low values) and low-high clusters (low values are mainly surrounded by high values) [32].

A second way to examine the spatial pattern of the data is by using the Getis and Ord $\mathrm{Gi}^{*}$ statistic. This way, we check if the spatial cluster patterns detected with the LISA method are confirmed by this second method, as well.

In addition, unlike the Moran's I statistic, which is a kind of correlation coefficient between observed values and locations, comparing if the value for each observation is similar to those that neighbour it, the $\mathrm{Gi}^{*}$ statistic measures the concentration of a spatially distributed variable comparing local averages to global averages. This index is calculated as follows (Eq. 4):

$$
G i^{*}=\frac{\sum_{i=1}^{n} w_{i j} x_{j}-x \sum_{j=1}^{n} w_{i j}}{\sqrt[S]{\frac{\left[n \sum_{i=1}^{n} w_{i j}^{2}-\left(\sum_{j=1}^{n} w_{i j}\right)\right]}{n-1}}}
$$

where: $x_{j}$ is the attribute value for feature $j ; w_{i j}$ is the spatial weight between feature $i$ and $j ; n$ is equal to the total number of features and: (Eq. 5, Eq. 6).

$$
\begin{aligned}
& \bar{X}=\frac{\sum_{j=1}^{n} x_{j}}{n} \\
& S=\sqrt{\frac{\sum_{j=1}^{n} x_{j}^{2}}{n}-\left(\bar{X}^{2}\right.}
\end{aligned}
$$

The $\mathrm{Gi}^{*}$ statistic is a $\mathrm{z}$-score so no further calculations are required. The resultant z-scores and pvalues tell us where features with either high or low values cluster spatially. This tool operates by addressing each feature within the context of neighbouring features. If large values of the examined variables are clustered close to region $\mathrm{I}$, then $\mathrm{Gi}^{*}$ will be large as well (hot spot).

The local sum for a feature and its neighbours is proportionally compared to the sum of all features. When the local sum is very different from the expected local sum, and the difference is too large to be the result of a random chance, a statistically significant z-score results.

For statistically significant positive z-scores, the larger the z-score, the more intense the clustering of high values (hot spot). For statistically significant negative $\mathrm{z}$-scores, the smaller the $\mathrm{z}$-score, the more intense the clustering of low values (cold spot).

This means that $\mathrm{Gi}^{*}$ statistic shows solely positive spatial correlation; 'high-high' clusters are indicated by positive spatial correlation, and 'low-low' clusters by negative ones. Therefore, the $\mathrm{Gi}^{*}$ statistic is a good way to detect clusters of high and low income level, to delimit centres and peripheries in a region and to examine the persistence of spatial disparities.

The main advantage of using the LISA, Getis and Ord $\mathrm{Gi}^{*}$ statistic over other methods of regional inequalities measurement consists in the fact that they are able to identify spatial clusters where incomes of neighbouring spatial units are highly autocorrelated. 
This means that there is a high and significant spatial interaction inside each detected spatial cluster.

The values resulted from the spatial autocorrelation analyses were calculated and illustrated with the help of the GeoDa Software version 1.6.2 and are explained in the section 3.3 , more thoroughly.

\section{RESULTS AND DISCUSSION}

\subsection{Overview on urban-rural inequalities: challenges and consequences}

With 9,262,851 inhabitants living in rural areas (46\% according to the 2011 Census) covering $207,522 \mathrm{~km}^{2}$ (87.1\%), Romania has one of the largest rural peripheries of the EU, after France, Germany, Poland and Italy [33]. The rural population is far from being equally distributed, some regions holding higher shares (South-Muntenia 58.6\%, North-East 56.8\% and South-West Oltenia 51.9\%) or a higher density like North-East region (63.2 inhabitants $/ \mathrm{km}^{2}$ ), in contrast with the western part of the country where the density of the rural population is just of 26.5 inhabitants $/ \mathrm{km}^{2}$.

Taking into consideration the quality of life of the rural population, Romania has the highest incidence of rural poverty in Europe (over 70\%), and one of the largest gaps in living and social standards between rural and urban areas [20]. In 2010 the absolute poverty rate was four times higher in rural than in urban areas. Furthermore, the gap between the two areas has also tended to deepen in the last years: in 2000 the absolute poverty in rural areas was less than two times higher than in urban areas, while in 2010 it was already four times [34]. One of the main reasons for rural poverty in Romania is the low education level and the relatively high rate of illiteracy [34], [35], [36].

According to the 2011 Census, only $4.7 \%$ of the stable population (10 years and older) living in rural areas has had a university degree (the percentage was $\mathbf{2 2 . 4 \%}$ in urban areas) while more than $3 \%$ has had no education whatsoever, $1.4 \%$ being illiterate.

According to the 2011 Census, $62.1 \%$ of households had access to running water, while the situation is even more critical in the case of the sewerage system, only $42 \%$ of rural households having access to the sewage network, while in the urban environment this index is $94.1 \%$.

The average Romanian income level in 2011 has had a median equalized income of 2037 Euro, which was the smallest value in the EU and around ten times lower than that of some developed western countries [37].

As we could expect there is also a large gap between urban and rural income levels: in 2011, the average income for urban households was $33.4 \%$ higher than that of rural households. One of the most frequently used methods of measuring income inequality is the Lorenz Curve and Gini Coefficient. The Lorenz curve for Romania - reaching a convex sharp shows that the "poorest" $10 \%$ of the population get only $3 \%$ of total incomes, or that the poorest $90 \%$ got about $71 \%$ of total income, implying that the remaining $29 \%$ of income goes to the richest $10 \%$ of the population (Fig. 1).

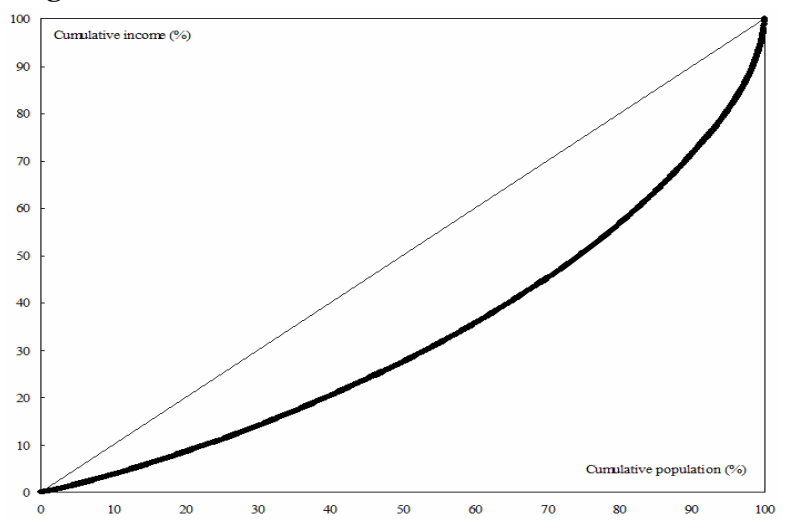

Fig. 1. The Lorenz curve for Romania, 2013 (source: [25].

In 2013 the income quintile ratio (S80/S20) was 6.7, which ranks Romania first in the EU 28 with the most unequal income distribution along with Greece (6.6), Spain and Latvia (6.3) and Lithuania (6.1) [37].

A second very convenient summary measure of the relative degree of income inequality in a country can be obtained with the Gini-coefficient. In the case of Romania, the Gini coefficient in 2013 was $36.9 \%$ representing one of the highest values after 2007, when it reached $37.5 \%$.

Considering a larger period of time, income inequality grew to a high extent. If in early nineties Romania was characterized by a low level of inequality (22.7\%), after only a decade of transition, parallel with the starting economic growth, the Gini-coefficient registered a slight increase, reaching a value of $35.3 \%$ one of the highest value in the early years of the 21st century. Usually the Gini-coefficient maintained a very high level all through the time of economic growth which strengthens those basic thoughts of equity that economic growth does not necessarily bring social welfare. Only in 2008 the Gini-coefficient started to decrease when Romania entered to economic recession as a consequence of the global economic crises. However, this short break has no major consequences on the overall evolution of the Romanian income distribution (Fig. 2).

In most cases subsistence agriculture carried out by individual farmers on fragmented lands represented one of the most important sources of household/individual budget protecting also some family from poverty and decreasing at the same time income inequality [38]. 


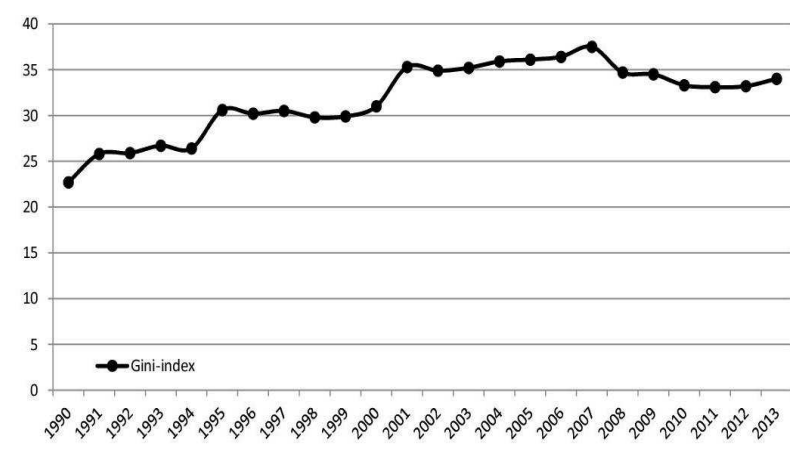

Fig. 2. Distribution of per capita household net income: Gini index 1990-2013 (source: [37]).

\subsection{Spatial clusters of local income}

Table 1 displays some statistical distributions of income per capita. There is an important uneven distribution of income per capita among the development regions of Romania. Well above the national average of 569 Lei per capita are the Capital region and the West (Banat) Development Region. In general, there is a clear west-east gradient in income distribution with the exception of Bucharest-Ilfov. This situation is reflected on the level of settlements as well.

Table 1. Distribution of income per capita categories for 2014 (in lei) at the level of development regions and settlements.

\begin{tabular}{|c|c|c|c|c|c|c|c|c|c|c|c|c|}
\hline \multirow{2}{*}{ Regions } & \multirow{2}{*}{$\begin{array}{l}\text { Aver } \\
\text { age } \\
\text { (lei) }\end{array}$} & \multicolumn{2}{|c|}{$<300$} & \multicolumn{2}{|c|}{$300-500$} & \multicolumn{2}{|c|}{$500-700$} & \multicolumn{2}{|c|}{$700-1000$} & \multicolumn{2}{|c|}{$>1000$} & \multirow{2}{*}{ Total } \\
\hline & & No. & $(\%)$ & No. & $(\%)$ & No. & $(\%)$ & No. & $(\%)$ & No. & $(\%)$ & \\
\hline $\begin{array}{l}\text { North-East } \\
\text { Moldova }\end{array}$ & 339 & 324 & 58.8 & 162 & 29.4 & 36 & 6.5 & 29 & 5.3 & 11 & 2.0 & 551 \\
\hline $\begin{array}{l}\text { South-East } \\
\text { (Black Sea) }\end{array}$ & 556 & 78 & 18.5 & 151 & 35.8 & 68 & 16.1 & 93 & 22.0 & 32 & 7.6 & 422 \\
\hline $\begin{array}{l}\text { South- } \\
\text { Muntenia }\end{array}$ & 503 & 117 & 19.6 & 237 & 39.8 & 133 & 22.3 & 79 & 13.3 & 30 & 5.0 & 596 \\
\hline $\begin{array}{l}\text { South-West } \\
\text { Oltenia }\end{array}$ & 452 & 117 & 25.3 & 239 & 51.6 & 46 & 9.9 & 46 & 9.9 & 15 & 3.2 & 463 \\
\hline West Banat & 902 & 18 & 4.6 & 66 & 17.0 & 89 & 22.9 & 150 & 38.7 & 65 & 16.8 & 388 \\
\hline $\begin{array}{l}\text { North-West } \\
\text { Transylvania }\end{array}$ & 579 & 38 & 7.8 & 212 & 43.5 & 86 & 17.7 & 109 & 22.4 & 42 & 8.6 & 487 \\
\hline $\begin{array}{l}\text { Centre } \\
\text { Transylvania }\end{array}$ & 715 & 8 & 1.7 & 136 & 28.3 & 119 & 24.8 & 151 & 31.5 & 66 & 13.8 & 480 \\
\hline $\begin{array}{l}\text { Bucharest- } \\
\text { Ilfov }\end{array}$ & 1837 & 0 & 0.0 & 1 & 1.4 & 0 & 0.0 & 38 & 55.1 & 30 & 43.5 & 69 \\
\hline Romania & 569 & 700 & 100.0 & 1204 & 100.0 & 577 & 100.0 & 695 & 100.0 & 291 & 100.0 & 3456 \\
\hline
\end{tabular}

While in North-East Moldova almost $60 \%$ of the settlements have earned an income per capita well below the national average and, therefore, can be categorized as poor, the same category contains only $4,6 \%$ of the settlements in West (Banat) and even no single settlement in the Capital region of BucharestIlfov. This situation reflects the existing of deep multiscalar income inequalities, seen in recent studies as an important obstacle for economic growth [39].

To our knowledge, Figure 3 displays the spatial distribution of NUTS- 5 level income per capita in Romania for the first time in the literature. The most striking picture is of important disparities among different parts of the country, particularly between the eastern and western regions. Income levels in the eastern and southern periphery - covering the development regions North-East Moldova, South-West Oltenia and South-Muntenia - are typically half or less than half of the Romania average (569 Lei/capita, around 129 Euro/capita).

Figure 3 also demonstrates that settlements with similar income levels cluster together: settlements with high (low) income are localized close to other settlements with high (low) income. The highest concentration of low-income settlements can be observed in the eastern and south-eastern parts of Romania. This category comprises 695 settlements (21.8\% of the total), including also some settlements which have recently changed their status from rural to urban. The only exceptions to this general picture are the suburban settlements with better job opportunities and quality of life (Table 2).

Settlements with the highest income per capita are concentrated in the agglomeration area of Bucharest, the southern and north-western part of the historical region Transylvania, and on the southwestern border region (West Banat) along with areas close the Black Sea Coast (south-eastern part of Romania).

Overall, the spatial distribution of local income per capita in Romania shows the importance of geographical position and proximity, suggesting the existence of strong spatial interactions and significant spatial autocorrelation. Therefore, we further test for inequality in the spatial distribution of local income using the Moran's I index. Taking into consideration the geographical configuration, size and shape of the analysed spatial units (NUTS-5), we have tested 
different spatial weight matrices and found highly robust results. Table 2 offers a detailed picture on income distribution for settlement categories. There is an important income gap between urban and rural settlements, while the situation of suburban settlements. While around $75 \%$ of urban settlements have an income per capita above the national average, only around $33 \%$ of rural settlements are in the same situation.

The situation of the suburban settlements which has profited from the increasing suburbanisation process - is better, around $60 \%$ of the settlements from this category having income levels higher than the national average.

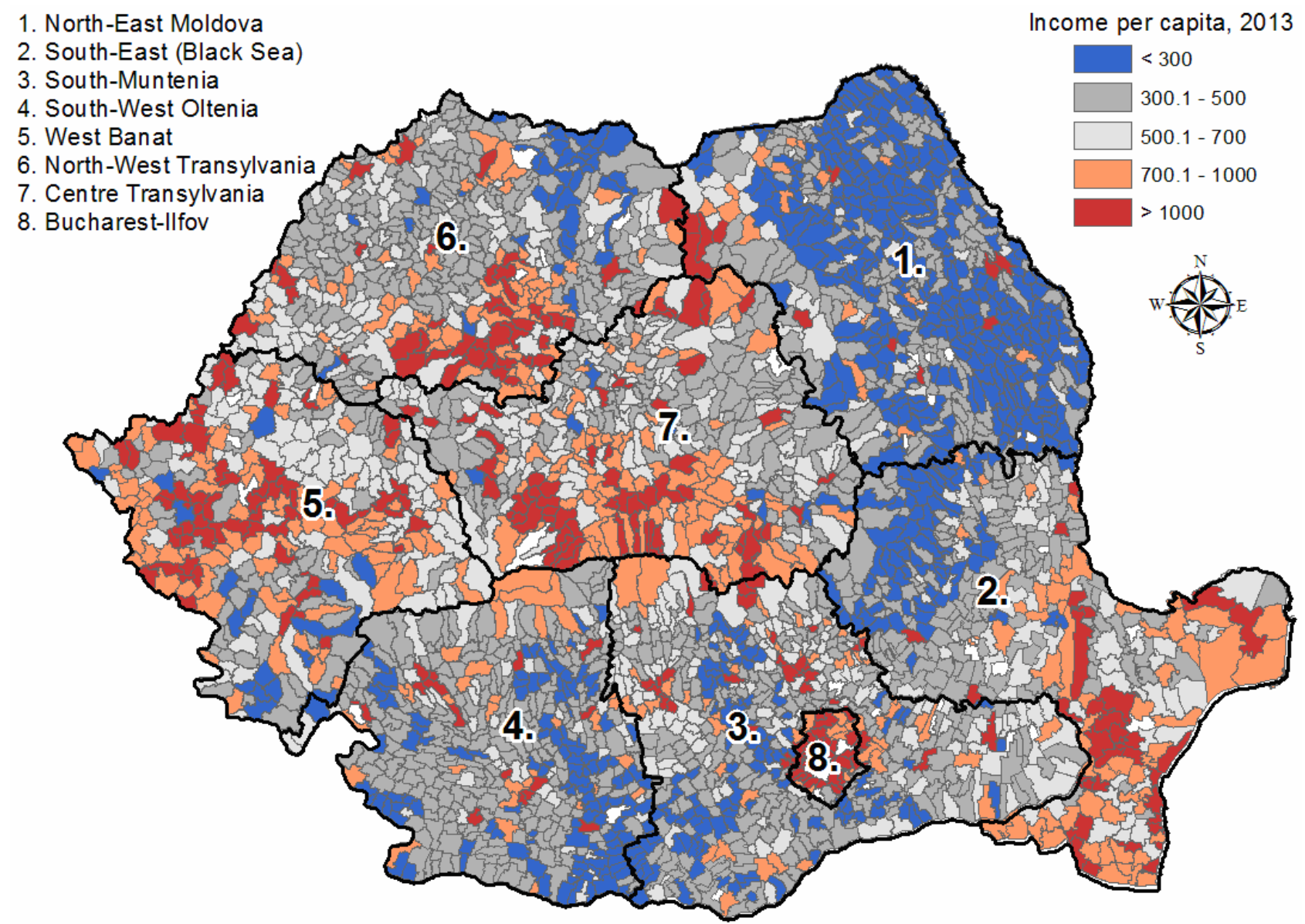

Fig. 3. Spatial distribution of income per capita (source: Regional Directorates General of Public Finance, 2013) [25].

Table 2. The distribution of income per capita at settlements and settlement categories.

\begin{tabular}{|c|c|c|c|c|c|c|c|c|c|c|c|}
\hline \multirow{2}{*}{$\begin{array}{l}\text { Category of } \\
\text { settlements }\end{array}$} & \multicolumn{2}{|c|}{$<300$ RON } & \multicolumn{2}{|c|}{$300-500$ RON } & \multicolumn{2}{|c|}{ 500-700 RON } & \multicolumn{2}{|c|}{ 700-1000 RON } & \multicolumn{2}{|c|}{ >1000 RON } & \multirow{2}{*}{ Total } \\
\hline & No. & $(\%)$ & No. & $(\%)$ & No. & $(\%)$ & No. & $(\%)$ & No. & $(\%)$ & \\
\hline Urban & 15 & 4.7 & 48 & 15.0 & 79 & 24.7 & 100 & 31.3 & 78 & 24.4 & 320 \\
\hline Suburban & 17 & 10.5 & 46 & 28.4 & 33 & 20.4 & 23 & 14.2 & 43 & 26.5 & 162 \\
\hline Rural & 668 & 24.8 & 1108 & 41.2 & 465 & 17.3 & 281 & 10.4 & 169 & 6.3 & 2691 \\
\hline Total & 700 & 22.1 & 1202 & 37.9 & 577 & 18.2 & 404 & 12.7 & 290 & 9.1 & 3173 \\
\hline
\end{tabular}

\subsection{Spatial patterns of income distribution}

\subsubsection{Spatial Autocorrelation of income per capita in Romania - The Global Spatial Autocorrelation}

The main question addressed in this section is whether the observed pattern of income inequalities in Romania is similar to other spatial patterns or not. If there is a tendency, for example, that NUTS 5 spatial units with low (high) income level tend to be surrounded by NUTS 5 units with low (high) income 82 level, or vice-versa, this would indicate a positive spatial autocorrelation [40]. The GeoDa software allows us to build a Moran Scatter plot with the calculation of Moran's I [32] (Eq. 1). In order to calculate and compare the Moran's I we used four spatial weights based on the queen contiguity and knearest neighbours' structure from the first to the fourth spatial lag order. In the significance filter, the value of $p$ was determined as 0.05 and the software was using the permutation test in order to delimit the significant spatial units. 
Thus, the number of permutations was set at 999. The graph represents the distribution of the statistical units of the analysis (Fig. 4).

As Figure 4 shows, the value of Moran's I calculated for the income level is higher (o.33) using the $k$-nearest neighbour distance weight than the Queen contiguity weight (0.29). Since the value is higher than zero, it suggests a positive spatial autocorrelation for the analyzed variable, which means that settlements with relatively high (respective low) per capita income are localized close to other areas with relatively high (respective low) per capita income. Thus, we could reject the null hypothesis as the $p$ value is statistically significant $(\mathrm{p}=0.0001)$ and the $\mathrm{z}$-core is positive (14.82

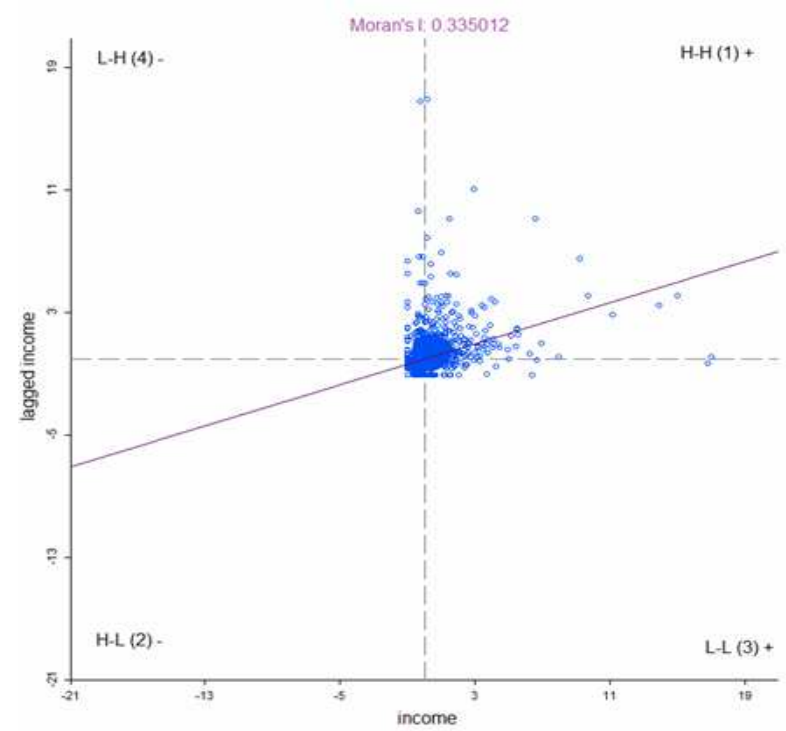

respectively 27.6). In fact, analyzing the results of Moran's I statistic, the income variable present a positive association between the original value and spatially lagged version in the case of all spatial weight taken into consideration (Table 3 ).

Global Moran's I statistic does not exactly show us the settlements characterized with a high (low) income level, but rather suggests that the spatial pattern of the analyzed variable is not random - there is more similarity by location than would be expected if the pattern was random [40]. Therefore in the next section we concentrate on the analysis of $\mathrm{Gi}^{*}$ statistic and LISA index.

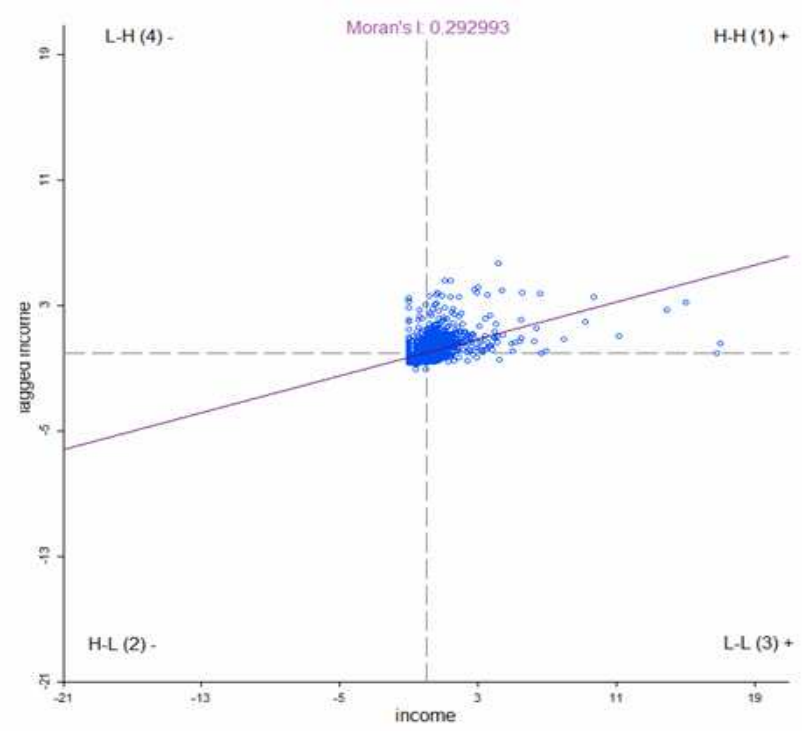

Fig. 4. Moran Scatter Plot for measuring income level (left k1-nearest neighbour weight, right queen 1 contiguity weight).

Table 3. Global spatial autocorrelation (Moran's I)*.

\begin{tabular}{llll} 
Ln Income $(\mathrm{t})$ & & & \\
\hline K-nearest $(\mathrm{k}=1)$ & 0.335012 & Queen first & 0.292993 \\
$\mathrm{~K}$-nearest $(\mathrm{k}=2)$ & 0.338852 & Queen second & 0.206477 \\
$\mathrm{~K}$-nearest $(\mathrm{k}=3)$ & 0.338243 & Queen third & 0.164334 \\
K-nearest $(\mathrm{k}=4)$ & 0.320836 & Queen fourth & 0.136786
\end{tabular}

*The calculation was carried out using the Geoda software.

\subsubsection{Spatial Autocorrelation of income per capita in Romania - The Gi* statistic and LISA index}

One of the most interesting feature of $\mathrm{Gi}^{*}$ statistic is its ability to detect clusters of high and low values of the index taken into consideration. Using $\mathrm{Gi}^{*}$ statistic (Eq. 4) at 5\% significance level, Figure 5 shows almost the same picture as in the cross-sectional analysis of income level, detecting significant local clusters of high values around the capital, Bucharest, in the southern and north-western part of Transylvania, in West Banat, and in the Black Sea region.

Local clusters of low values comprise the poorest rural areas: almost the entire region of NorthEast Moldova and large portions of the region SouthWest Oltenia. Overall, these results reveal the existence of strong spatial inequality among the Romanian settlements. Taking into consideration the significant high and low values (in total 901 settlements) $32.6 \%$ of the settlements belong to core areas while the rest of $67.4 \%$ can be considered as peripheries. The Local Indicator of Spatial Association (LISA) - applying queen 1 contiguity weight - also allows us to consider local effects and identifies pockets of spatial outliers or atypical localizations. In contradiction to the $\mathrm{Gi}^{*}$ statistic based cluster map, the LISA index identifies all four cluster types (Table 4), offering more details on the spatial patterns of economic interaction. Appendix 1 presents the LISA significance map for the income per capita in 2013 using and comparing all the 4-4 weights mentioned before. In fact the spatial patterns of the clusters are almost the same, however - different from the results of Global Moran's I - using contiguity 
weights we got a much comprehensive picture on the existing spatial relationships. This could be attributed to the way/algorithm each weights are created: while the k-neighbour weight is based on the distance between the points, the queen contiguity weight is based on the common borders. As we could observe the local income distribution in Romania is spatially differentiated and autocorrelated. The results suggest the appearance of the same centre-periphery model, and the high persistence of spatial inequality among the Romanian settlements as we have demonstrated with the help of $\mathrm{Gi}^{*}$ statistic. Appendix 1 and 2 show that

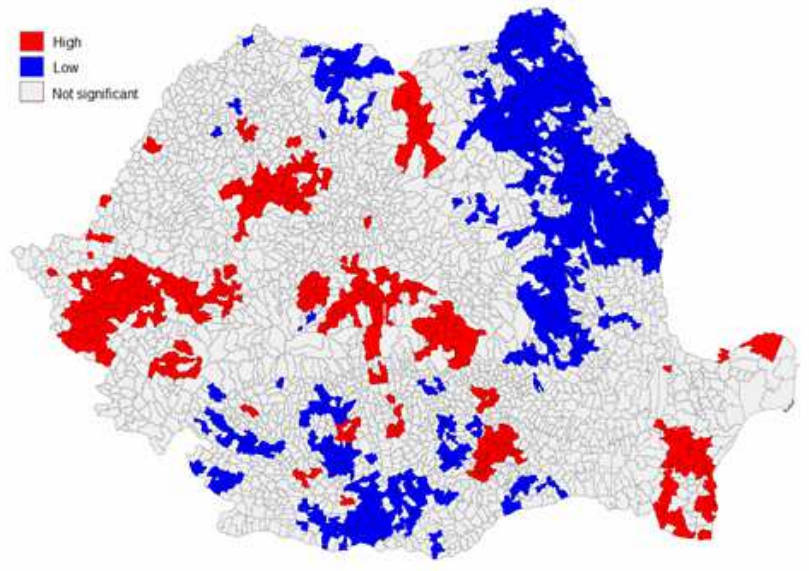

settlements from the low-low clusters are concentrated mainly in the eastern and south-western parts of the country. These results are in accordance with the spatial patterns of GDP per capita and HDI distribution at NUTS 3 level, as revealed in a recent study [41]. In contrast, high-high clusters can be found in the immediate surroundings of the already mentioned large urban areas: Bucharest, Constanța, Sibiu, Timișoara and Cluj.

A particular interest for us was related to the association of spatial outliers (HL and LH types) to certain spatial structures (Table 5).

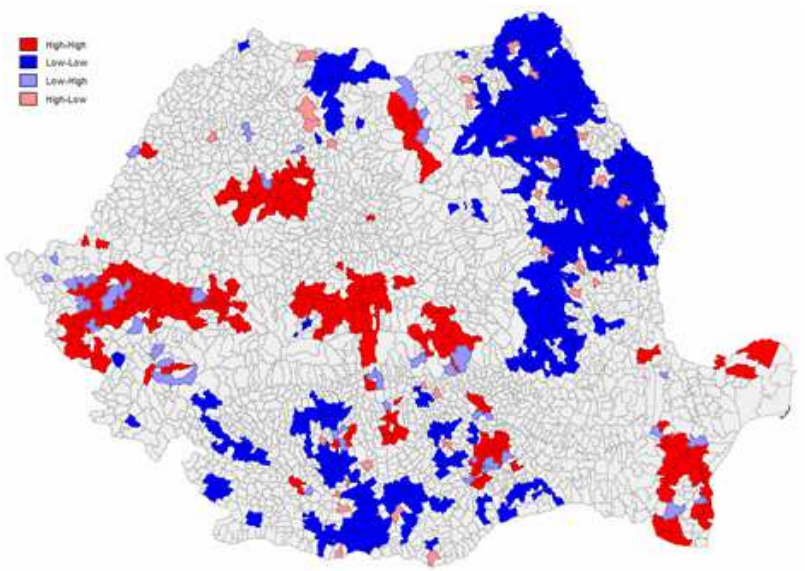

Fig. 5. Cluster map for income per capita, using $\mathrm{Gi}^{*}$ statistic (left) and LISA index (right).

Table 4. Cluster types identified with $\mathrm{Gi}^{*}$ and LISA.

\begin{tabular}{|c|c|c|c|c|}
\hline \multirow{2}{*}{ Cluster type } & \multicolumn{2}{|c|}{ Gi* statistic } & \multicolumn{2}{|c|}{ LISA index } \\
\hline & No. of settlements & $(\%)$ & No. of settlements & $(\%)$ \\
\hline High-High & 294 & 32.6 & 258 & 28.5 \\
\hline Low-Low & 607 & 67.4 & 577 & 63.7 \\
\hline Low-High & - & - & 38 & 4.2 \\
\hline High-Low & - & - & 33 & 3.6 \\
\hline Total & 901 & 100 & 906 & 100 \\
\hline
\end{tabular}

Table 5. The correspondence between Local Moran's I clusters and spatial structure typology.

\begin{tabular}{|c|c|c|}
\hline Cluster & Interpretation & Type of spatial structure \\
\hline High-high & $\begin{array}{l}\text { NUTS } 5 \text {-areas and their neighbours register income per capita } \\
\text { values significantly above the national average }\end{array}$ & $\begin{array}{l}\text { Fragmented spatial structure, establishment } \\
\text { of a large core region }\end{array}$ \\
\hline High-low & $\begin{array}{l}\text { NUTS 5-areas have income per capita significantly above the } \\
\text { average, while their neighbours register values significantly below } \\
\text { the national average }\end{array}$ & $\begin{array}{l}\text { Polarized spatial structure, with one } \\
\text { dominant core area }\end{array}$ \\
\hline Low-high & $\begin{array}{l}\text { NUTS 5-areas have income per capita significantly below the } \\
\text { average, while their neighbours register values significantly above } \\
\text { the national average }\end{array}$ & Spatial structures with reversed polarization \\
\hline Low-low & $\begin{array}{l}\text { NUTS 5-areas and their neighbours register income per capita } \\
\text { significantly below the national average }\end{array}$ & $\begin{array}{l}\text { Fragmented spatial structure, establishment } \\
\text { of a large peripheral region }\end{array}$ \\
\hline
\end{tabular}

Settlements with polarized spatial structures (high-low clusters) can be usually found in the already mentioned core regions, all of them (with one exception) being situated within rural areas.

On the other hand, a completely reverse situation can be observed in the case of the low-high 84 clusters, defined as areas with reversed polarization these are usually small and medium size cities with lower income levels, surrounded by rural areas with higher income levels.

The polarized spatial structures presented above are representative for the less developed regions 
of Romania, where urban centres with high income level are surrounded by large rural areas with low income levels.

\section{CONCLUSION}

This paper is based on the application of spatial autocorrelation techniques for measuring the spatial differentiation of local, NUTS 5-level income in Romania. In particular, we applied both the Global Moran's I statistic, as well as the LISA and $\mathrm{Gi}^{*}$ statistic in order to demonstrate in a multitude of ways the existence of spatial autocorrelation for the income per capita. By applying the LISA index on the spatial distribution of income per capita, we tested and compared two different methods of weights with several orders (in the case of queen contiguity weight) and numbers (in the case of k-nearest neighbour distance weight) in order to identify much accurately homogenous, well defined spatial clusters. Specifically, we used spatial statistics to define the core areas and peripheries in Romania.

Our findings are in line with the results of other studies using different methods [42], [43]. The additional value of our paper is related to the high spatial resolution of the identified spatial income patterns. Another important contribution of our paper is represented by the mapping of local income distribution, which provides more empirical evidence for public authorities. This way, spatial planning policies can more precisely identify their areas of intervention for the design and implementation of a range of development targets.

The literature reveals multiple factors behind the geographical clustering of income [12]: socioeconomic interaction among neighbouring spatial units through knowledge spillovers, commuting, economies of scale, transfer payments, national policies or socio-cultural characteristics. Our study confirms that geographical location is important for the income performance of settlements. Especially areas that are close to the international and national market centres are in a more favourable situation. In addition, we proposed a new interpretation for the identified clusters by combining the typology of the clusters with specific spatial structures. In the future, this interpretation can fuel the theoretical discussions on spatial polarisation and peripheralization, offering methodological rigour, which is absent in the main literature on this topic. More exactly, the cluster typology developed in our study allows for the designation of peripheral areas at a very high spatial resolution (NUTS 5). Its main weakness is that the identified clusters cannot offer an explanation on the causal factors determining the evolution of peripheral areas. In addition, the crosssectional character of the data set imposes a further limitation for the study. We assume that the use of longer time series would result in a modified spatial configuration of core areas and peripheries. To overcome this limitation we employed two different methods to give more robustness to the identified spatial clusters. However, further efforts should be done in the future to determine the public availability of financial data, which in turn would enable a better tailoring of spatial planning policies addressing questions of economic and social backwardness.

The used ESDA technique revealed significant positive global spatial autocorrelation: areas with relatively high (respectively low) per capita income are localized close to other areas with relatively high (low) per capita income. In this sense, the most extended peripheral areas (low-low clusters) are located in the eastern and south-western parts of the country which comprise the entire region of North-East Moldova, the northern part of Transylvania, and partially SouthMuntenia and South-West Oltenia regions. From this strongly polarized spatial structure (high-low clusters) dominated by large peripheries (mostly rural settlements) a few developed core areas emerge, most of them being small and medium size cities.

On the contrary, the most extended core areas (high-high clusters) are concentrated around six large urban centres: Bucharest, Constanța, Braşov, Sibiu, Timișoara and Cluj-Napoca. Moreover, the analysis suggests the importance of geographic location and proximity as a causal factor of income distribution: high income level in one settlement is influenced by high income level in the neighbouring settlements (and viceversa) and any other changes in the evolution of the income will greatly influence the same changes in values in other locations. But further investigations are needed to demonstrate that proximity is a causal factor of income distribution.

\section{ACKNOWLEDGMENTS}

This research was supported by an EAHERDIF grant to the Centre for the Study of Democracy at the Babeş-Bolyai University (PN-III-P4-ID-PCE-20160729).

\section{REFERENCES}

[1] Haar, L. N. (2010), Industrial restructuring in Romania from a bilateral trade perspective: manufacturing exports to the EU from 1995 to 2006, In: Europe-Asia Studies, vol. 62, no. 5, pp. 779-805.

DOI: $10.1080 / 09668136.2010 .481386$

[2] Popescu, C. (2014), Deindustrialization and urban shrinkage in Romania. What lessons for the spatial policy? In: Transylvanian Review of Admnistrative Sciences, vol. 42E, pp. 181-202.

[3] Benedek, J., Lembcke, A. C. (2017), Characteristics of recovery and resilience in the 
Romanian regions. In: Eastern Journal of European Studies, vol. 8, no. 2, pp. 95-126.

[4] Surd, V., Kassai, I., Giurgiu, L. (2011), Romania disparities in regional development. In: Refe, F - Ozturk, M (eds) 2 nd International Geography Symposium - Mediterranian Environment 2010, Procedia Social and Behavioral Sciences, 19, pp. 21-30. [5] Benedek, J., Kurkó, I. (2012), Convergence or divergence? The Position of Romania in the Spatial Structure of the European Union. In: Transylvanian Review, vol. 21, no. 2, pp. 116-125.

[6] Benedek, J., Cristea, M., Szendi, D. (2015), Catching up or falling behind? Economic convergence and regional development trajectories in Romania. In: Romanian Review of Regional Studies, vol. 11, no. 1, pp. 15-34.

[7] Török, I. (2014), From growth to shrinkage: the effects of economic change on the migration processes in rural Romania. In: Landbauforshung, vol. 64, no. 34, pp. 195-206. DOI: 10.3220/LBF_2014_195-206

[8] Benedek J., Ivan, K. (2018), Remote sensing based assessment of variation of spatial disparities. In: Geographia technica, vol. 13, no. 1, pp. 1-9. DOI: 10.21163/GT_2018.131.01

[9] Amarante, V. (2014), Revisiting Inequality and Growth: Evidence for Developing Countries. In: Growth and Change, vol. 45, no. 4, pp. 571-589. DOI: 10.111/grow.12057

[10] Panzera, D., Postiglione, P. (2014), Economic Growth in Italian NUTS 3 Provinces. In: Annals of Regional Science, vol. 53, no. 1, pp. 273-293. DOI: 10.1007/soo168-014-0628-y

[11] Atkinson, A. B. (2015), Inequality. What can be done? Harvard University Press.

[12] Rodríguez-Pose, A., Tselios, V. (2015), Toward inclusive growth: is there regional convergence in social welfare? In: International Regional Science Review, vol. 38, no. 1, pp. 30-60. DOI: 10.1177/0160017613505-201

[13] Benedek, J., Hărănguş, I., Man, T. (2016), Commuting patterns in Romania. Case study on Cluj County. In: Regional Statistics, vol. 6, no. 2. pp. 38-52. DOI: 10.15196/RSo6203

[14] Goschin, Z., Constantin, D. L. (2010), The geography of the financial crisis and policy response in Romania. In. Gorzelak, G., Goh, C.H. (eds.) Financial crisis in Central and Eastern Europe: from similarity to diversity. Euroreg, pp. 161-190. ISBN 978-38-664-9356-8.

[15] Szendi, D. (2013), The Convergence Process and the Effects of the Economic Crisis in Central-Eastern Europe. In: Romanian Review of Regional Studies, vol. 9, no. 1. pp. 79-84.

[16] Benedek, J., Kocziszky, Gy. (2015), Paths of convergence and polarization in the Visegrád countries. In: Lang, T., Henn, S., Sgibnev, W., Ehrlich, K., (eds.): Understanding Geographies of Polarization and Peripheralization. Perspectives from Eastern
Europe and Beyond. Palgrave/MacMillan, Basingstoke. 352 pp. 217-234.

[17] Török, I. (2013), Regional development in Romania: shaping European convergence and local divergence. In: Regions, no. 291, pp. 25-27. DOI: 10.1080/13673882.2013.10739982

[18] Ranga, M. (2012), Stimulating $R \& D$ and innovation to address Romania's economic crisis, In: European Planning Studies, vol. 20, no. 9, pp. 14971523. DOI: 10.1080/o9654313.2012.709145

[19] Benedek, J., Moldovan, A. (2015), Economic convergence and polarisation: towards a multidimensional approach. In: Hungarian Geographical Bulletin, vol. 64, no. 3, pp. 187-203. DOI: 10.15201/hungeobull.64.3.3

[20] Sandu, D. (2011), Social disparities in the regional development and policies of Romania. In: International Review of Social Research, vol. 1, no. 1, pp. 1-30. DOI: 10.1515/irsr-2011-0001

[21] Benedek, J., Veress, N. (2013), Economic Disparities and Changes in the Convergence of the Romanian NUTS 2 and NUTS 3 Regions. In: Romanian Review of Regional Studies, vol. 9, no. 1, pp. 85-90.

[22] Ianoș, I., Petrișor, Al., Zamfir, D., Cercleux, A. L., Stoica, I. V., Tălângă, C. (2013), In search of a relevant index measuring territorial disparities in a transition country. Romania as a case study. In: Erde, vol. 144, no. 1, pp. 69-81. DOI: 10.12854/erde-144-5 [23] Anselin, L. (1998), Exploratory spatial data analysis in a geocomputational environment. In: P.A. Longley, S. M. Brooks, R. McDonnell, and W. Macmillian (eds.) Geocomputation: A Primer, pp. 7794. New York: Wiley and Sons.

[24] INS - National Institute of Statistics, Bucharest, Romania.

[25] ANAF - Regional Directorates General of Public Finance, Bucharest, Romania.

[26] György, A., Câmpeanu, E., György, A. E. (2011), Financial strategies for the Romanian local public administration. In: Transylvanian Review of Administrative Sciences, Issue No. 34E/October, pp. 114-124.

[27] Goodchild, F. M. (1986), Spatial autocorrelation, Published by Geo Books, Norwich.

[28] Cliff, A. D., Ord, J. K. (1973), Spatial autocorrelation. Monographs in spatial environmental systems analysis. London: Pion, 178 p.

[29] Cliff, A. D., Ord, J. K. (1969), The problem of spatial autocorrelation. In: Scott AJ (ed) London Papers in Regional Science, Studies in Regional Science. London: Pion, pp. 25-55.

[30] Moran, P. A. P. (1950), Notes on continuous stochastic phenomena. In: Biometrika, vol. 37, pp. 17-23.

DOI: 10.1093/biomet/37.1-2.17

[31] Badaloni, M., Vinci, E. (1988), Contributi all'analisi dell'autocorrelazione. In: Spaciale Metron vol. 46, pp. 119-140. 
[32] Anselin, L. (1995), Local Indicators of spatial association LISA. In: Geographical Analysis, vol. 27, no. 2, pp. 93-115. DOI: 10.1111/j.1538-4632.1995.tboo338.x [33] Benedek, J., Török, I. (2014), County-level demographic disparities in Romania. In: Transylvanian Review, vol. 23, no. 2, pp. 138-147.

[34] Precupetu, I. (2013), Inequality trends in Romania. In: Calitatea Vieţii, vol. 24, no. 3, pp. 249-276.

[35] Tara, S. (2013), Social inequalities and poverty in current Romania. In: Theoretical and Applied Economics, vol. 20, no. 2, pp. 129-144.

[36] Domnisoru, C. (2014), The largest drop in income inequality in the $E U$ during the Great Recession: Romania's puzzling case. Conditions of Work and Employment Series No. 51, ILO, http://www.ilo.org/wcmsp5/groups/public/--edprotect /---protrav/---travail/documents/publication/wcms_ 313840.pdf

[37] Eurostat - European Union Statistical Database. [38] Marginean, I. (ed.) (2006), First European Quality of Life Survey: Quality of life in Bulgaria and Romania. Luxembourg: Office for Official Publications of the European Union. http://edz.bib.unimannheim.de/daten/edz-ma/esl/o6/efo667_en.pdf
[39] Tselios, V. (2009), Growth and Convergence in Income per Capita and Income Inequality in the Regions of the EU. In: Spatial Economic Analysis, vol. 4, no. 3, pp. 343-370. DOI: 10.1080/17421770903114711 [40] Torres, M., Vosti, S. P., Maneta, M. (2011), Spatial pattern of rural poverty: an exploratory analysis in the Sao Francisco River Basin, Brazil. In: Nova Economia vol. 21, pp. 45-66. DOI: 10.1590/So103-63512011000100002

[41] Benedek, J. (2015), Spatial differentiation and core-periphery structures in Romania. In: Eastern Journal of European Studies, vol. 6, no. 1, pp. 49-61.

[42] Rusu, A., Groza, O. (2018), Territorial data aggregation and trends of regional economic convergence in Europe. A geo-statistical analysis for the 2003-2014 period. In: Transylvanian Review, vol. 27, no. 1, pp. 73-93.

[43] Nagy, J., Benedek, J. (2018), Towards a balanced metropolitan governance: combating the "back-door" status of peripheral rural areas. In: Transylvanian Review, vol. 27, no. 1, pp. 3-20. 


\section{APPENDIX 1. MORAN'S I STATISTIC}

1.1. Cartogram of spatial clusters representing per capita income using Lisa index and applying $k$-nearest neighbour from first to fourth order at 0,01 significance level (left) and o,05 significance level (right).

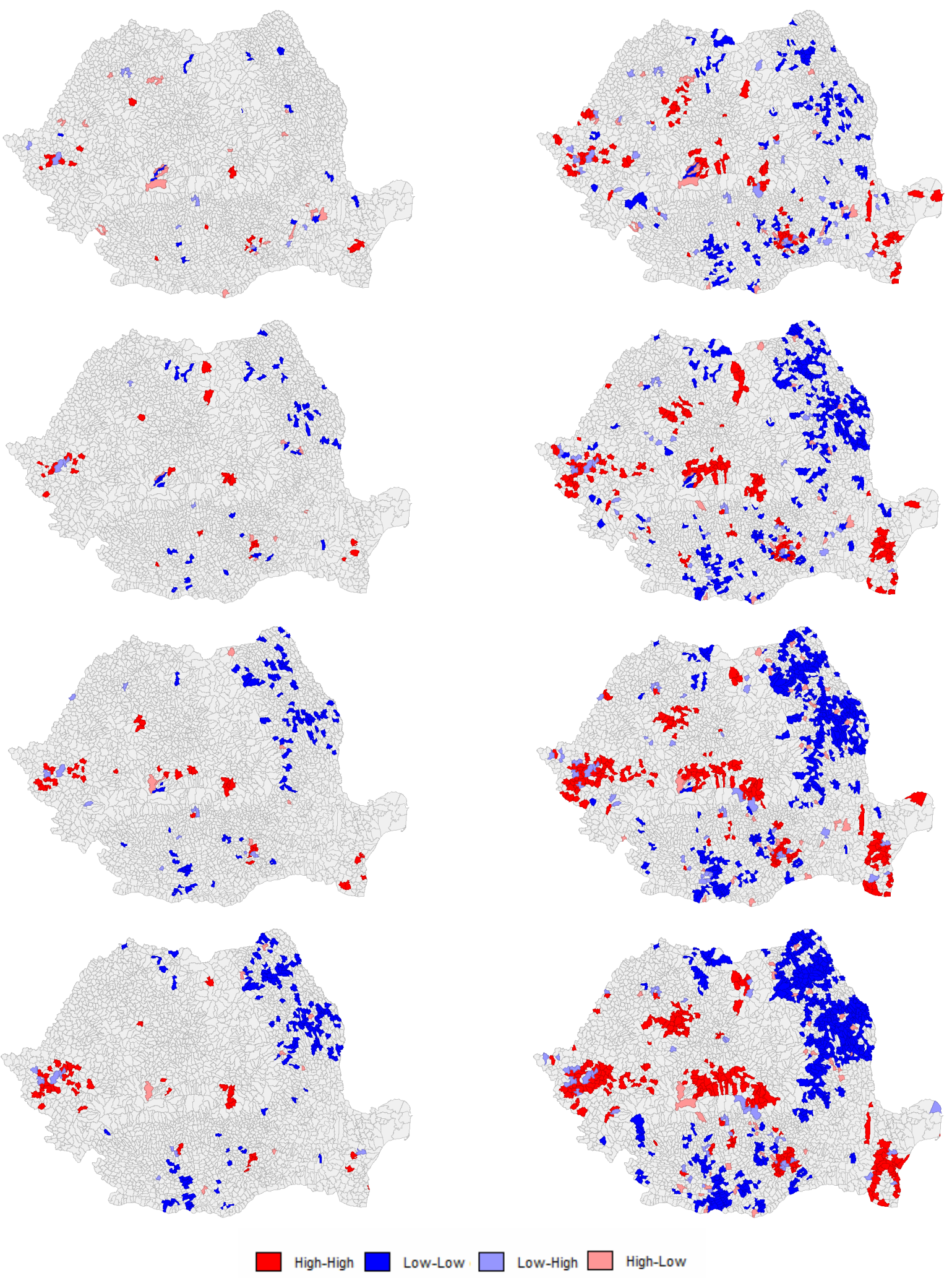


1.2. Cartogram of spatial clusters representing per capita income using Lisa index and applying queen contiguity from first to fourth order with o,01 significance level (left) and o,05 significance level (right).
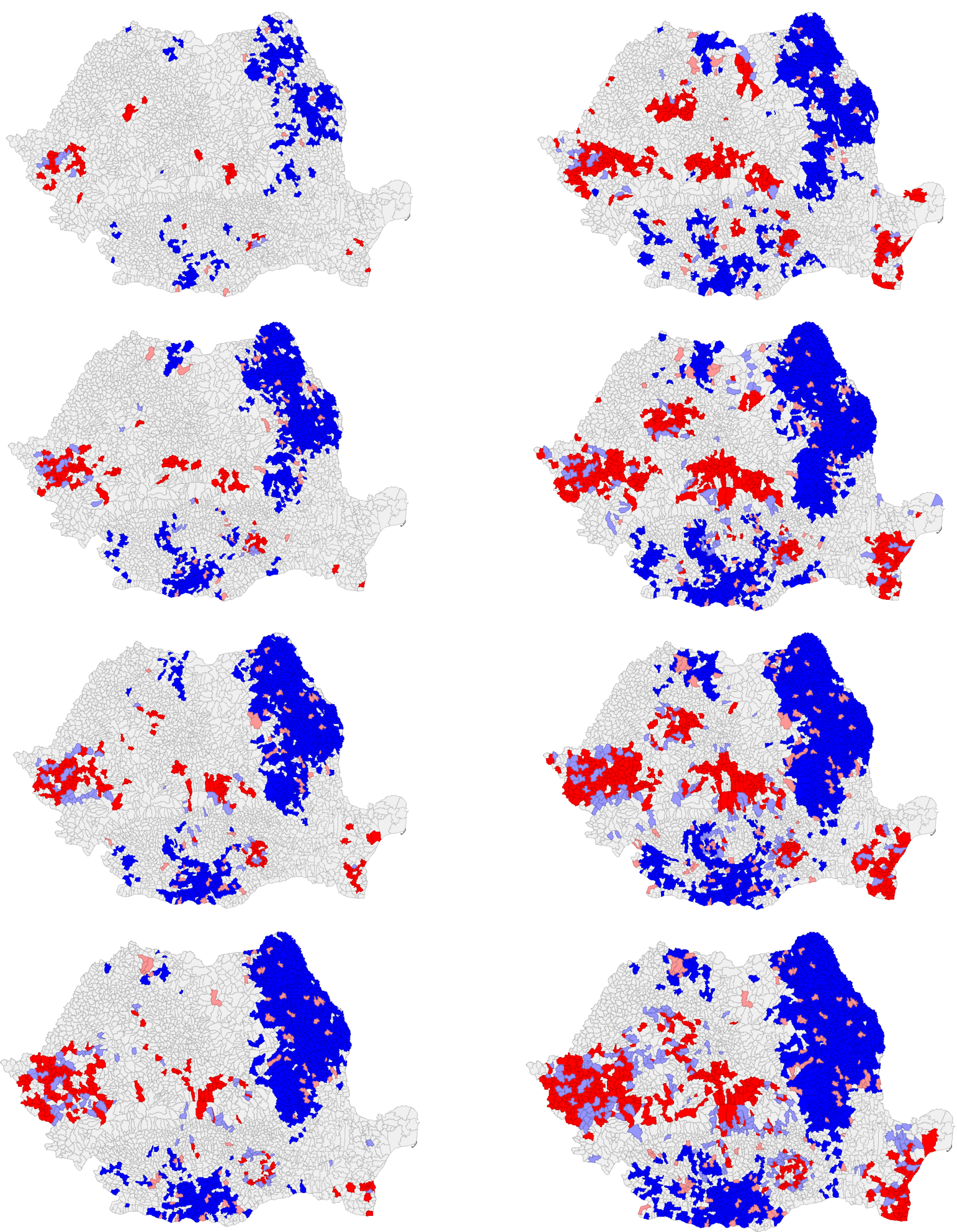

High-High

Low-Low

Low-High

High-Low 


\section{APPENDIX 2. GI* STATISTIC}

2.1. Cartogram of spatial clusters representing per capita income using $\mathrm{Gi}^{*}$ statistic and applying $k$-nearest neighbour from first to fourth order with o,01 significance level (left) and 0,05 significance level (right).
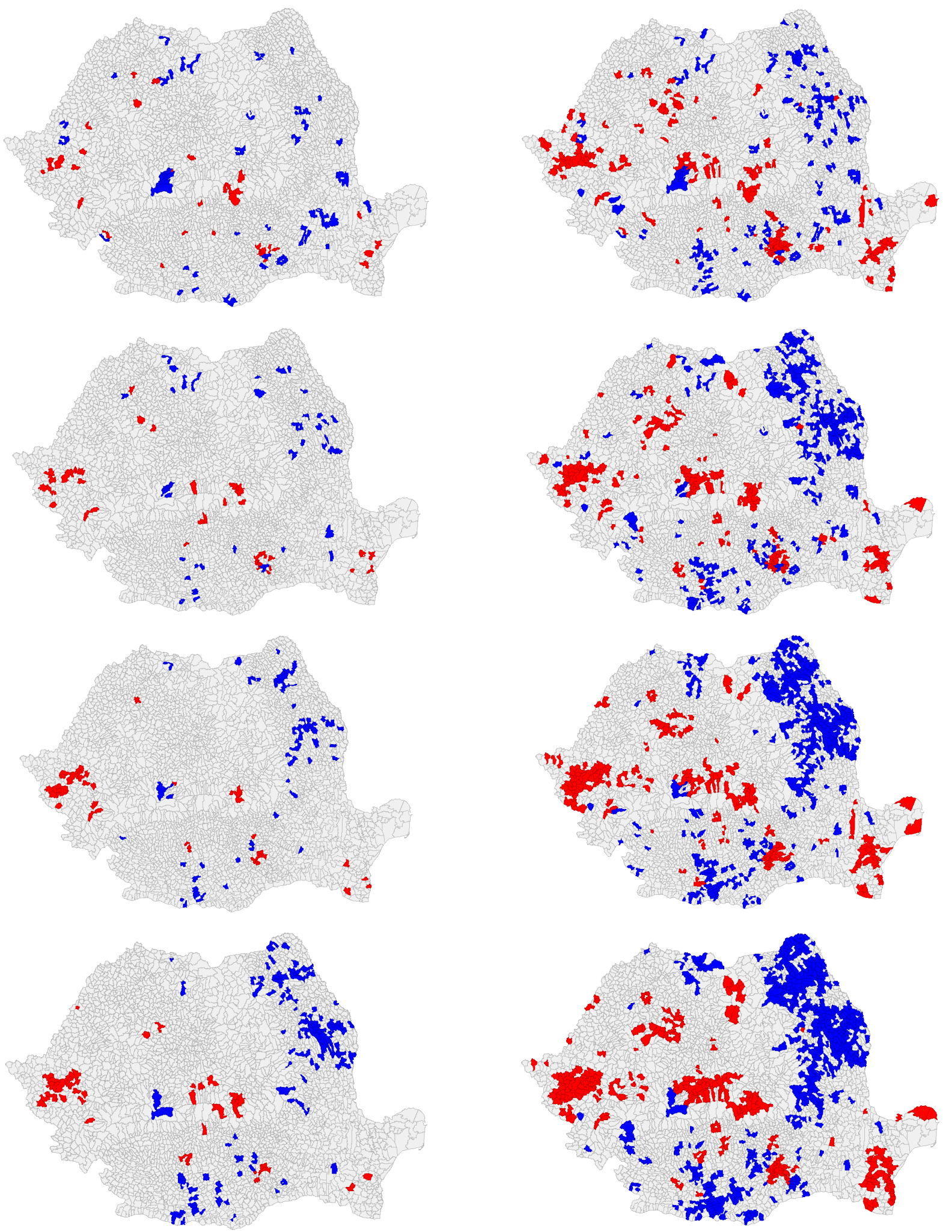
2.2. Cartogram of spatial clusters representing per capita income using $\mathrm{Gi}^{*}$ statistic and applying queen contiguity from first to fourth order with 0,01 significance level (left) and 0,05 significance level (right).
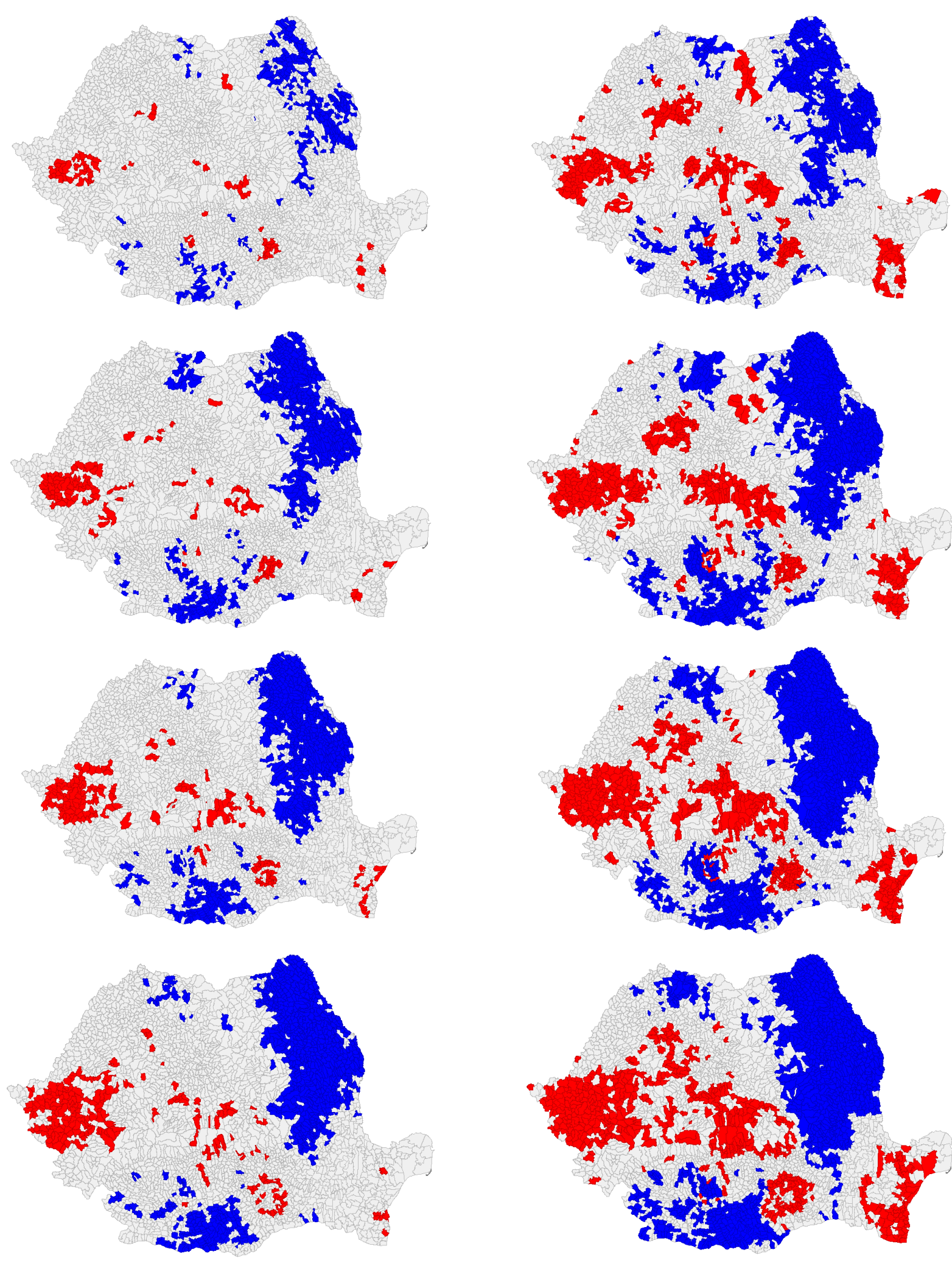

High-High

Low-Low 